\title{
The Effect of Social Network on Retail Buying Behaviour in Chennai City
}

\section{P. Aasish Nahar}

\begin{abstract}
Retail is one of the significant sectors in India seeking attention for the investment. It is also approaching a lot of foreign direct investment. A blast of societal mass media networks, in the last decade has erupted tradition information seeking in market. Online networking, for example, Face book twitter, you tube, and Google has added another social measurement to the web. This paper depends on impact of web based life on retail purchasing conduct.
\end{abstract}

Keywords : Retail Industry, social network, buyer behavior and advertisement.

\section{INTRODUCTION}

$T_{1}$ he retail exchange is on the stop of the producers offer colossal amounts of product to retailers, and outlets attempt to provoke the ones equivalent amounts of product to buyers. Changed monetary and political surroundings in India has achieved a flood of huge scope of contestants into the US quickly developing retail venture at some phase in the past couple of years, without uncertainty, the retail endeavour in India is in the throes of radical rebuilding. The crucial drivers of exchange are developing per capita pay, developing GDP, accessibility of customer fund and hence irreversible. Retailing in surely understood experience comprises of business exercises which may be associated with looking for and selling of items and contributions to shutting buyers for their very own utilization - beginning from Bread margarine to vehicles to array to carrier tickets.

\section{A. Retail Industry in India}

Today, a sizable part of India's younger populace favours exclusive items. With the unfold of satellite TVs and noticeable media, metropolitan existence fashion developments have feast throughout the countryside regions additionally. The buying performance of the Indian central elegance particularly the younger populace for garb, consumption outdoor and longing for contemporary styles has released new potential outcomes for retail development even inside the rustic zones.

In this manner, $85 \%$ of the retail development which become concentrated distinctly inside the metros has started to invade toward littler towns and urban areas. Level II towns are as of now accepting centered consideration of retailers and the inverse littler urban areas and even towns are probably going to take a crack at inside the coming years. This is a positive pattern, and the commitment of those level

Revised Manuscript Received on December 05, 2019.

* Correspondence Author

Dr. P. Aasish Nahar*, Assistant Professor, A M Jain college, Chennai, India. Email: aasish.p.nahar@gmail.com
II towns to by and large sorted out retailing deals is relied upon to develop to twenty-25\%. One of the fundamental reasons at the back of the blast of retail and its divided nature inside the United States of America is the truth that retailing is presumably the main state of camouflaged joblessness/underemployment inside the United States.

Given the already over-crowded agriculture sector, and the stagnating manufacturing area, and the difficult nature and comparatively low wages of jobs in both, many million Indians are surely compelled into the services area.

Given the effectively packed farming part, and the stagnating fabricating territory, and the troublesome nature and similarly low wages of occupations in both, numerous million Indians are most likely constrained into the administrations region

\section{B. Social Media}

When searched in Google for the word social media, About 7,12,00,00,000 results appeared on screen in 0.75 seconds. As per Google search online networking implies sites and applications that empower clients to make and share content or to partake in informal communication.

In the Cambridge lexicon, the essential meaning of web-based social networking alludes to all sites and application that empowers individuals to make as well as offer substance and that offer the chance to take an interest in long range informal communication. In any case, this definition can depict all sites found on the web these days. Along these lines, a few people have an increasingly confined meaning of social average and consider it as equivalent to social 10 systems administration. A few people don't considerably think about online journals as a feature of web based life. This dissimilarity of feelings can rapidly get befuddling

\section{REVIEW OF LITERATURE}

The youthful have crucial acquiring power, are convincing on the obtaining getting choice inside their family much of the time the examples Etters in the general public. Their normal propelled training, regular computerized proficiency and love of informal communities infers that the media have much better learning into where they are and what they are enthusiastic about, regardless, different blocks and challenges to the productive usage of sites for advertising still remain. Drury found changing into a ground-breaking advertising channel is an astounding piece of data to various associations and affiliations. 
Weinberg promoting is a technique that attracts in and engages people and associations to propel their destinations, things or administrations and organizations through online social channels and to speak with a lot of bigger system that in all probability will not are out there by ways for normal business enterprise channel. It partners professional centres, associations and with a large gathering of observers of influencers and patrons.

As per Retail Business report 2013 the bit of sorted out retail is $8 \%$ of the all retail market to urge better plan within making pie of the asian nation retail in India.

Evans supposed that the impact of social media life is bigger before all phases of the purchasing procedure. The Users of web based stages get the opportunity to get some answers concerning various customers past encounters with the web store or specific product. This can prompt getting the clients attention, raising enthusiasm for the referenced item or a genuine want to proceed to buy the thing.

Hanlon Patrick et al expressed that social media is significant for advertisers since it enables them to exchange legitimately with Customers, which thus connects with purchasers straightforwardly with organization brands .Lee fights that social media has turned out to be immeasurably prevalent for " normal customers " since it enables anybody to communicate with substance or convey it . This network is hugely superior to the conventional configuration of single direction correspondence among media and its objective gathering.

Drell found uses web sites undoubtedly make relationship with people from its target measurement rather than standard media where dialogs between the medium and the gathering of onlookers are unthinkable. By and by, web based life outlets, for instance, Facebook and Twitter have made it straightforward for clients to post item audits and contact other likely people in their systems.

\section{RESEARCH METHODOLOGY}

\section{A. Purposes of the Research}

The purposes of the research were:

1. To learn the present levels of social media involvement among the retail customers.

2. To test the relationship between Social medial impact on buying behaviour of retails customers.

3. To provide suggestive measures for optimization of effectiveness and efficiency of the employees in selected retail outlets.

Area of Research: Chennai

Data Collection Method: -Survey Method.

-Prime Data: used survey from.

-Subordinate Data: Collected from Books, Websites, articles, dissertation and thesis.

\section{Sampling}

Sample Size: - 246

Sample Design:-Random Sampling

Analysis layout: - Exploratory \& depictive

\section{RESULTS AND DISCUSSIONS}

Graph 1: Showing the Gender of the respondents

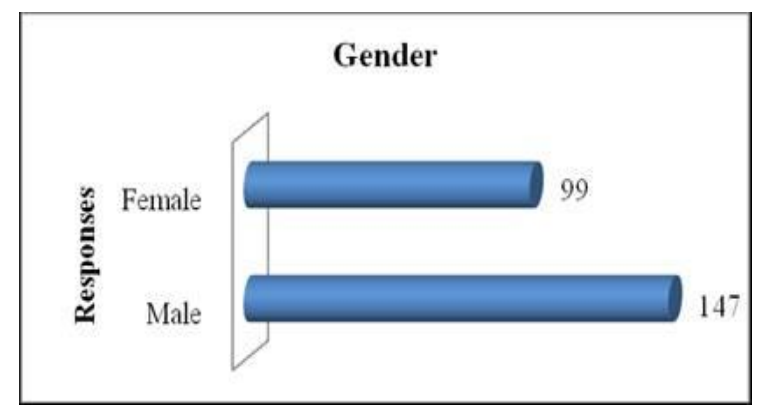

From the above graph it can be inferred that among total respondents 99 are Female respondents and 147 are Male respondents.

Table 1: Showing the education background of the respondents

\begin{tabular}{|l|c|c|}
\hline \multicolumn{1}{|c|}{ Particulars } & Responses & Percentage (\%) \\
\hline School & 57 & 23.2 \\
\hline Diploma & 60 & 24.4 \\
\hline UG & 38 & 15.4 \\
\hline PG & 49 & 19.9 \\
\hline Others & 42 & 17.1 \\
\hline Total & 246 & 100 \\
\hline
\end{tabular}

From the above table, it can be understood that, 24.4 percentage of respondents are diploma holders, 23.2 percentage of the respondents have completed the education of schooling, 19.9 percentage of employees have completed their education of PG, 17.1 belongs to the others category and 15.4 percentage are Degree holders.

Graph 2: Showing the respondents buy from various outlets.

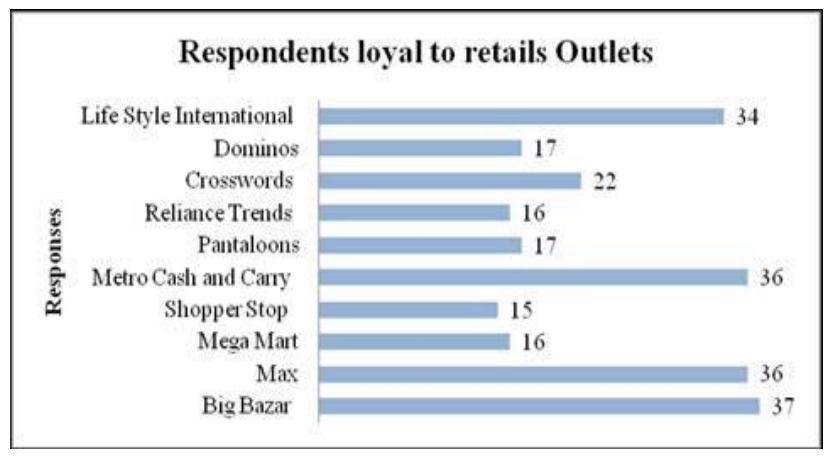

From the above graph, it can be deduced that, 37 respondents buy from Big Bazaar, 36 respondents buy from both metro cash and carry and Max retails, 34 respondents buy from Life style international, 17 respondents buy from Pantaloons and Dominos, 16 respondents buy from reliance trends and mega mart, 15 respondents buy from shoppers stop.

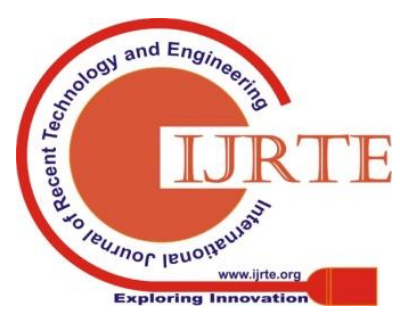


Graph 3: Showing sites Influence you to attempt New Brands

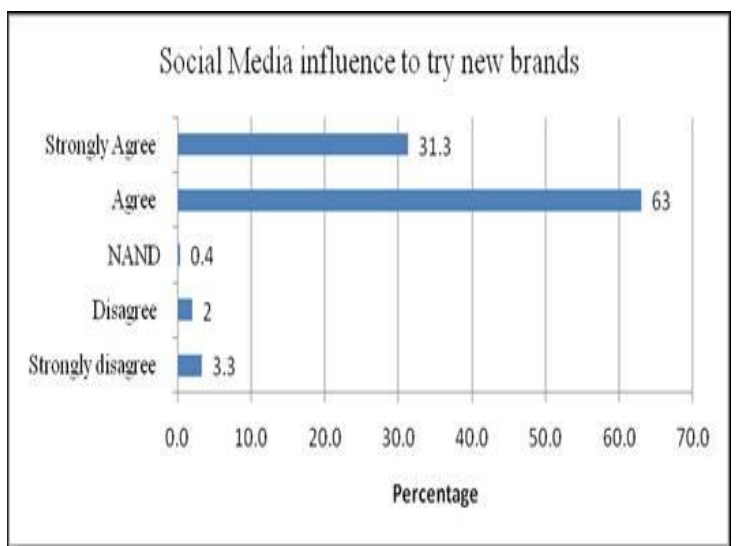

From the graph, it tends to be deciphered that, 63 percentage of responses respondents concur Social Media impact to attempt new marks, 31.3 level of respondents concede to Social Media impact to attempt new marks, 3.3 level of respondents differ on Social Media impact to attempt new marks.

Graph 4: Showing responses on search for related Information on Social Media Before a Purchase?

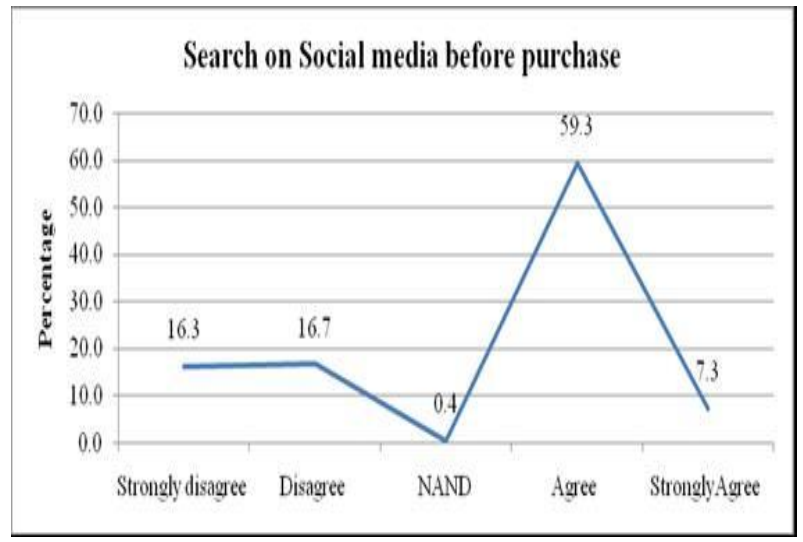

it very well may be deciphered that, 59.3 level of respondents concede to Search on Social media before buy, 16.7 level of respondents differ on Search on Social media before buy.

Graph 5: Showing responses on searching is Easier Via Social Media Comparing to Mass Media (E.G. TV, Radio, Newspaper, and so on)?

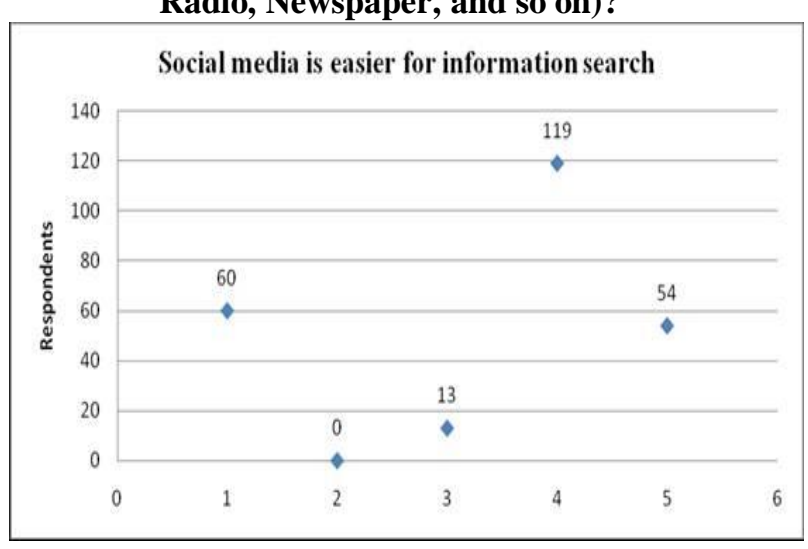

Interpretation: From the above chart, it very well may be deciphered that, 119 respondents concede to looking is Easier Via Social Media Comparing to Mass Media, 13 respondents have given a nonpartisan reaction

Graph 6: Showing responses on Social Media Triggers to Purchase in retail market?

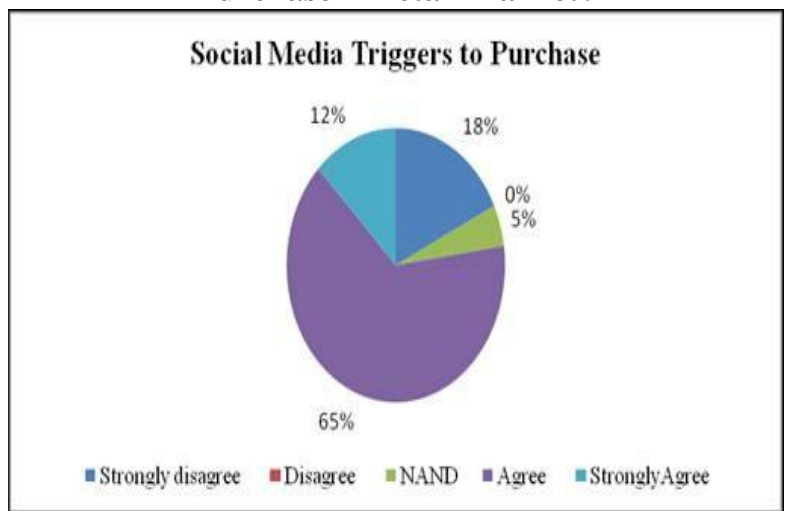

Interpretation: From the above table and graph, it can be interpreted that, 65 percentage of respondents agree on Social Media Triggers to Purchase, 5 percentage of respondents have given a neutral response

\section{A. Hypothesis Testing}

1. There is important disparity in amount of social media impacting the retail buying behaviour

2. There is cogent disparity in amount of social media impacting the retail buying behaviour

\section{Table - 2}

\begin{tabular}{|c|c|c|c|c|c|c|}
\hline $\begin{array}{l}\text { Organizations/ } \\
\text { Openness }\end{array}$ & $\begin{array}{c}\text { Very } \\
\text { low } \\
\text { value }\end{array}$ & $\begin{array}{c}\text { Fairly } \\
\text { Low } \\
\text { Value }\end{array}$ & $\begin{array}{c}\text { Fairly } \\
\text { high } \\
\text { value }\end{array}$ & $\begin{array}{l}\text { Highly } \\
\text { Valued }\end{array}$ & Total & $\begin{array}{c}\text { Chi } \\
\text { square } \\
\text { test }\end{array}$ \\
\hline Big Bazaar & 5 & 9 & 46 & 125 & 185 & \multirow{10}{*}{$\begin{array}{c}\mathrm{P}<0.000 \\
1\end{array}$} \\
\hline $\operatorname{Max}$ & 4 & 5 & 39 & 132 & 180 & \\
\hline Mega Mart & 3 & 9 & 29 & 39 & 80 & \\
\hline Shoppers stop & 4 & 9 & 16 & 46 & 75 & \\
\hline $\begin{array}{l}\text { Metro cash \& } \\
\text { carry }\end{array}$ & 0 & 12 & 156 & 12 & 180 & \\
\hline Pantaloons & 6 & 8 & 11 & 60 & 85 & \\
\hline $\begin{array}{l}\text { Reliance } \\
\text { Trend }\end{array}$ & 3 & 2 & 64 & 11 & 80 & \\
\hline Cross Words & 0 & 0 & 7 & 103 & 110 & \\
\hline Dominos & 0 & 5 & 19 & 61 & 85 & \\
\hline $\begin{array}{l}\text { Life Style } \\
\text { International }\end{array}$ & 0 & 14 & 82 & 74 & 170 & \\
\hline Total & 25 & 73 & 469 & 663 & 1230 & \\
\hline
\end{tabular}

Interpretation: P-value of 0.0001 is less than the significance level justifying rejecting the null hypothesis. 
Acceptance of alternate hypothesis means difference in amount of social media impacting the retail buying behaviour

\section{CONCLUSION}

This research had given a reasonable sign that purchasing behaviour is changing quickly and advertisers needed to change their systems as per the situation. Different studies report that Social network is generally used each and every one. So now the business people need to concentrate on their limited time techniques. They need to transform them as indicated by the taste and inclinations. Along these lines, appropriate plan of promoting methodology needs a general comprehension of this standard of conduct. However the above study reflects that the majority of the customers, irrespective of their ages depend on the social media for related information search for retail buying. Businessperson must utilize social sites efficient way for expanding accomplishment of their item in market.

\section{REFERENCES}

1. Indian retail market -opening more doors

2. Maya Salimath , Dr. B Rose Kavitha Competency mapping: tool for escalating service encounters"(study with reference to selected retail companies in Bangalore).

\section{AUTHOR PROFILE}

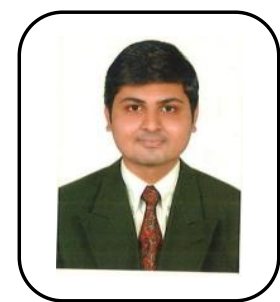

Dr. P. Aasish Nahar is an Assistant professor in the Department of commerce, A.M.Jain College, University of Madras, Chennai, Tamil Nadu, India. $\mathrm{He}$ is the 7th UniversityRank Holder in PG and has 4 years of teaching experience. His Area of interest isInvestments and marketing. He has presented research paper in various international and national level conferences and also published research paper in various reputed journal. 